ISSN : $2302-1590$

E-ISSN: $2460-190 \mathrm{X}$

ECONOMICA

Journal of Economic and Economic Education Vol.2 No.2 (106 - 115)

\title{
PENGARUH KESADARAN MEREK, ASOSIASI MEREK DAN PERSEPSI KUALITAS TERHADAP KEPUTUSAN PEMBELIAN PC TABLET SAMSUNG GALAXI DI KOTA PADANG
}

\author{
Yonaliza \\ Mahasiswa Program Studi Pendidikan Ekonomi STKIP- PGRI Sumbar \\ Jl. Gunung Pangilun No.1, Padang Sumatera Barat \\ Email: yona.liza1@yahoo.com \\ Yulna Dewita Hia \\ Dosen Program Studi Pendidikan Ekonomi STKIP- PGRI Sumbar \\ Jl. Gunung Pangilun No.1, Padang Sumatera Barat \\ Email: yoel nahia@yahoo.com
}

Submited: 2014.01.27 Reviewed: 2014.02.29 Accepted: 2014.04.12

http://dx.doi.org/10.22202/economica.2014.v2.i2.223

\begin{abstract}
This research aims to to analyse influence brand awareness, brand association and quality perception to decision of purchasing of PC tablet of Smsung galaxi in Padang. Population in this research is consumer which have used PC Tablet of Samsung Galaxi in Padang. Intake of sampel by using method of accidental sampling, that is chosening sampel pursuant to population element occurence or people which data is easy collected by researcher. Data analysis used is analysis of multiregression and hypothesis test by using t test. Result of this research indicate that : By parsial awareness of brand, brand association and perception of kaulitas have an effect on to decision of purchasing of PC Tablet of Samsung Galaxi in Padang. Moreover, variable contribution Awareness of brand, brand association, perception of its quality of to decision of purchasing of PC Tablet of Samsung Galaxi in Padang is equal to 77,5\%. While 22,5 influenced by other variable. Become, besides awareness of brand, brand association, and perception of its quality of there are also influence of other factor which influence decision of purchasing.
\end{abstract}

\begin{abstract}
Abstrak
Penelitian ini bertujuan untuk menganalisis pengaruh Kesadaran merek, asosiasi merek dan persepsi kualitas terhadap keputusan pembelian PC tablet Samsung galaxi di kota padang. Jenis penelitian ini adalah penelitian kausatif yang bertujuan untuk mengetahui pengaruh Kesadaran merek, asosiasi merek dan persepsi kualitas terhadap keputusan pembelian PC tablet Samsung galaxi di kota padang. Populasi dalam penelitian ini adalah konsumen yang pernah menggunakan PC Tablet Samsung Galaxi di Kota Padang. Pengambilan sampel dengan menggunakan metode accidental sampling, yaitu memilih sampel berdasarkan elemen populasi (orang atau kejadian) yang datanya mudah diperoleh peneliti. Analisis data yang digunakan adalah analisis regresi berganda dan uji hipotesis dengan menggunakan uji t.Hasil penelitian ini menunjukkan bahwa : Secara parsial kesadaran merek, asosiasi merek dan persepsi kaulitas berpengaruh terhadap keputusan pembelian PC Tablet Samsung Galaxi di Kota Padang. Selanjutnya kontribusi sumbangan variabel Kesadaran merek, asosiasi merek, persepsi kualitas terhadap keputusan pembelian PC Tablet Samsung Galaxi di Kota Padang adalah sebesar 77,5\%. Sedangkan 22,5 dipengaruhi oleh variabel lain. Jadi, selain kesadaran merek, asosiasi merek, dan persepsi kualitas terdapat juga pengaruh faktor lain yang mempengaruhi keputusan pembelian.

Keywords: brand awareness, brand association, quality perception
\end{abstract}




\section{PENDAHULUAN}

Alasan Orang Memakai Komputer Tablet — @ iniunik.web.id yaitu Komputer tablet sedang booming. Gadget berbasis layar sentuh ini kian mendapat tempat di hati konsumen. Lalu apa alasan utama orang-orang senang memakai tablet semacam iPad, Galaxy Tab atau Motorola Xoom. Biro riset terkemuka, Nielsen, coba meneliti alasan mengapa orang memakai tablet. Berikut hasilnya :

\section{Tabel 1. Kegunaan Tablet Menurut Biro Riset Terkemuka Nielsen}

\begin{tabular}{|c|c|}
\hline Kegunaan Tablet & Persentase $(\%)$ \\
\hline 1. Mudah dibawa ke mana-mana & $31 \%$ \\
\hline Interface/sistem operasi gampang digunakan & $21 \%$ \\
\hline Startup/off yang cepat & $15 \%$ \\
\hline 4. Nyaman digunakan & $12 \%$ \\
\hline 5. Ukuran yang kompak & $12 \%$ \\
\hline 6. Bisa digunakan di berbagai tempat & $12 \%$ \\
\hline 7. Performa cepat & $11 \%$ \\
\hline 8. Menyukai fiturnya seperti aplikasi atau kalender & $10 \%$ \\
\hline 9. Ringan bobotnya & $7 \%$ \\
\hline
\end{tabular}

Sumber : detikINET dari Fortune, Jumat (6/5/2011), Maret 2013

Melihat tren baru dari konsumen seperti itu dan besarnya jumlah penduduk Indonesia, perusahaan perusahaan yang bergerak dalam teknologi komputer berlomba lomba mengeluarkan produk PC Tablet andalannya masing masing. Perusahaan perusahaan komputer yang memasarkan produk mereka di Indonesia antara lain: Acer, Apple, Samsung, Axioo, Dell dll. Banyaknya perusahaan yang melempar produk mereka ke pasaran menciptakan persaingan yang tingggi dan keras dalam pasar Indonesia.

Berdasarkan survey pendahuluan diperoleh data penjualan PC Tablet sejak Februari 2012 sampai dengan Juli 2012 dari J-Bros Computer sebagai salah satu distributor tempat penjualan PC Tablet di kota padang sebagai berikut :

Tabel 2.Daftar Penjualan PC TabletPer Agustus 2012 - Januari 2013

\begin{tabular}{|c|c|c|c|c|c|c|c|c|c|c|c|c|c|c|c|c|c|c|c|}
\hline & \multicolumn{4}{|c|}{ J-Bros Computer } & \multicolumn{6}{c|}{ Maxindo Computer } & \multicolumn{6}{c|}{ Kharisma Computer } \\
\cline { 2 - 10 } & Aulan & Ags-12 & Sekt-12 & Nov-12 & Des-12 & Jan-13 & Ags-12 & Sep-12 & 0kt-12 & Nov-12 & Des-12 & Jan-13 & Ags-12 & Sep-12 & Okt-12 & Nov-12 & Des-12 & Jan-13 \\
\hline Samsung Galaxi & 4 & 6 & 7 & 6 & 9 & 6 & 6 & 5 & 8 & 7 & 8 & 6 & 4 & 5 & 6 & 4 & 5 & 3 \\
\hline Axioo & 2 & 6 & 3 & 6 & 4 & 7 & & & & & & & & & & & & \\
\hline Speedup & - & - & 3 & - & 2 & 3 & & & & & & & & & & & & \\
\hline ZTE & 1 & 1 & - & 4 & 2 & 2 & & & & & & & & & & & & \\
\hline IPAD2 & 2 & 4 & 6 & 5 & 6 & 6 & & & & & & & & & & & & \\
\hline Advan & & & & & & & 4 & 6 & 5 & 5 & 3 & 4 & & & & & & \\
\hline
\end{tabular}

Sumber : J-Bros Computer, Maret 2013

Berdasarkan Tabel 1 di atas dapat dijelaskan bahwasanya terjadi fluktuasi penjualan untuk PC Tablet dari bulan Agustus 2012 - Januri 2013. Dimana fenomena keputusan pembelian konsumen atas produk PC Tablet di kota Padang yang terbanyak adalah pada PC Tablet Samsung Galaxi. Hal ini mengindikasikan semakin tinggi minat konsumen terhadap PC
Tablet Samsung Galaxi dalam 6 bulan terakhir. Namun permasalahannya yaitu terjadinya fluktuasi volume penjualan dari bulan ke bulan. Terjadinya perubahan yang berfluktuasi volume penjualan Galaxy Samsung tentunya disebabkan oleh banyak faktor. Penulis menduga faktor yang berkemungkinan mempengaruhi keputusan pembelian Samsung galaxi dikota Padang 
adalah kesadaran merek, asosiasi merek dan persepsi kualitas.

Dalam situasi persaingan yang sangat ketat seperti ini, guna mempertahankan volume penjualan dan penguasaan pasar, perlu adanya strategi yang tidak hanya didasarkan pada kebutuhan konsumen (costumer oriented), tetapi juga para pesaing yang mengincar sasaran konsumen yang sama (competition oriented). Diharapkan perusahaan jeli dalam melihat berbagai peluang yang ada dan mengantisipasi berbagai ancaman yang muncul. Untuk itu diperlukan suatu kebijakan pemasaran yang baik dan diperhitungkan oleh perusahaan.

Menurut Aaker (1991) seperti yang dikutip oleh Durianto (2001:4) ekuitas merek dapat dikelompokkan ke dalam lima kategori yaitu :

1. Kesadaran merek menunjukan kesanggupan seorang calon pembeli untuk mengenali atau mengingat kembali bahwa suatu merek merupakan bagian dari kategori produk tertentu.

2. Asosiasi merek mencerminkan pencitraan suatu merek terhadap suatu kesan tertentu dalam kaitannya dengan kebiasaan, gaya hidup, manfaat, atribut produk, geografis, harga, pesaing, selebritis, dan lain-lain.

3. Persepsi kualitas mencerminkan persepsi pelanggan terhadap keseluruhan kualitas/keunggulan suatu produk/jasa layanan berkenaan dengan maksud yang diharapkan.

4. Loyalitas merek mencermikan tingkat keterikatan konsumen dengan suatu merek produk.

5. Aset-aset merek lainnya

Berdasarkan data-data yang diperoleh dapat ditarik kesimpulan bahwa dalam Tren Brand Value selama 1 tahun terakhir Brand Value PC Tablet menduduki Top Brand Value. Selain itu, konsumen merasa tingkat kepuasan yang diperoleh ketika menggunakan PC Tablet juga mengalami kenaikan, yang diketahui dari peringkat Top Brand Index PC Tablet yang menandakan semakin meningkatnya ekuitas merek yang diukur oleh tingkat kesadaran merek, persepsi kualitas dan asosiasi merek yang mengarah kepada terjadinya peningkatan keputusan pembelian konsumen terhadap produk PC Tablet

\section{Keputusan Pembelian}

Menurut Peter dan Olson (1999:162) keputusan pembelian adalah proses pengintegrasian yang mengkombinasikan pengetahuan untuk mengevaluasi dua atau lebih perilaku alternatif dan memilih salah satu diantaranya. Sedangkan menurut Kotler (2005:202) karakteristik pembeli dan proses pengambilan keputusannya akan menimbulkan keputusan pembelian.

Keputusan untuk membeli yang diambil oleh konsumen sebenarnya merupakan kumpulan dari sejumlah keputusan. Schiffman dan Kanuk (2007: 485) mendefenisikan bahwa keputusan adalah seleksi terhadap dua pilihan alternatif atau lebih. Dengan kata lain, pilihan alternatif harus tersedia bagi seseorang ketika mengambil keputusan. Seseorang pemasar harus menguasai berbagai hal yang dapat mempengaruhi pembeli dan mengembangkan suatu pengertian bagaimana sebenarnya seorang konsumen membuat keputusan. Kotler dan Keller (2009: 188) mengatakan dalam tahap evaluasi konsumen membentuk preferensi antar merek dalam kumpulan pilihan. Konsumen mungkin juga membentuk maksud untuk membeli merek yang paling disukai. Sementara Setiadi (2003: 332) mengatakan pengambilan keputusan konsumen adalah proses pengintegrasian yang mengkombinasikan pengeahuan untuk mengevaluasi dua atau lebih perilaku alternatif dan memilih salah satu diantaranya. Hasil dari proses pengintegrasian ini ialah suatu pilihan (choice) yang disajikan secara kognitif sebagai keinginan berperilaku.

Jadi dapat disimpulkan keputusan pembelian konsumen dapat diartikan 
sebagai tindakan yang diambil konsumen dalam mengkombinasikan pengetahuan untuk mengevaluasi dua atau lebih perilaku alternatif dan memilih salah satu diantaranya dalam usaha memicu kebutuhan dengan cara melakukan pembelian produk maupun jasa.

\section{Faktor Yang Mempengaruhi Keputusan Pembelian}

Menurut Kotler dan Keller (2009:178) terdapat beberapa faktor yang mempengaruhi keputusan pembelian konsumen yaitu rangsangan pemasaran yang terdiri dari produk dan jasa, harga, distribusi dan komunikasi, kemudian rangsangan lain berupa ekonomi, tekonologi, politik dan budaya, selanjutya dipengaruhi psikologi konsumen yang dilihat dari motivasi, persepsi, pembelajaran dan memori serta karakteristik konsumen yang dilihat dari faktor budaya, sosial, pribadi dan psikologis dan proses pengambilan keputusan pembelian yang menimbulkan keputusan pembelian tertentu yang terdiri dari pengenalan masalah, pencarian informasi, evaluasi alternartif, keputusan pembelian, serta perilaku pasca pembelian.

Ekuitas merek dapat mempengaruhi rasa percaya diri konsumen dalam pengambilan keputusan pembelian atas dasar pengalaman masa lalu dalam penggunaan atau kedekatan, asosiasi dengan berbagai karakteristik merek (Durianto, dkk, 2001:6). Semakin kuat ekuitas merek suatu produk, semakin kuat daya tariknya untuk menggiring konsumen mengkonsumsi produk tersebut dan pada akhirnya akan mengarah pada keputusan pembelian produk.

Menurut Aaker (1991) seperti yang dikutip oleh Durianto (2001:4) ekuitas merek dapat dikelompokkan ke dalam lima kategori yaitu :

1. Kesadaran merek menunjukan kesanggupan seorang calon pembeli untuk mengenali atau mengingat kembali bahwa suatu merek merupakan bagian dari kategori produk tertentu.
2. Asosiasi merek mencerminkan pencitraan suatu merek terhadap suatu kesan tertentu dalam kaitannya dengan kebiasaan, gaya hidup, manfaat, atribut produk, geografis, harga, pesaing, selebritis, dan lain-lain.

3. Persepsi kualitas mencerminkan persepsi pelanggan terhadap keseluruhan kualitas/keunggulan suatu produk/jasa layanan berkenaan dengan maksud yang diharapkan.

4. Loyalitas merek mencermikan tingkat keterikatan konsumen dengan suatu merek produk.

5. Aset-aset merek lainnya

Beberapa pemasar menganggap bahwa pada saat ini persaingan harga bukanlah suatu hal yang utama. Seiring berjalannya waktu, konsumen modem tampaknya mulai mengalihkan perhatiannya pada kualitas dan gengsi. Mereka rela mengeluarkan uang lebih hanya untuk mendapatkan sebuah barang bermerek terkenal. Selain bergengsi, konsumen menganggap bahwa barang bermerek terkenal mempunyai kualitas yang lebih baik dibanding barang merek lain yang kurang terkenal, walaupun pada kenyataannya tidaklah selalu begitu. Disinilah letak kekuatan ekuitas merek. Ekuitas merek yang kuat diharapkan dapat mempengaruhi konsumen untuk menjatuhkan pilihan pada suatu produk tertentu meski harga yang ditawarkan tidaklah murah.

\section{Merek}

Pada dasarnya suatu merek juga merupakan janji penjual untuk secara konsisten menyampaikan serangkaian ciriciri, manfaat, dan jasa tertentu kepada para pembeli.merek yang baik, juga menyampaikan jaminan tanbahan berupa jaminan kualitas.

Jadi dapat disimpulkan dari ketiga defenisi tersebut bahwa merek mengidentifikasi pembuat atau penjual dari suatu produk. Merek juga merupakan janji penjual untuk menyampaikan kesimpulan sifat, manfaat, dan jasa spesifik secara konsisten kepada pembeli. 
Tjiptono (2008:104) mengatakan merek sendiri digunakan untuk beberapa tujuan, yaitu :

1. Sebagai identitas, yang bermanfaat dalam diferensiasi atau membedakan produk suatu perusahaan dengan produk pesaingnya. Ini akan memudahkan konsumen untuk mengenalinya saat berbelanja dan saat melakukan pembelian ulang.

2. Alat promosi, yaitu sebagai daya tarik produk.
3. Untuk membina citra, yaitu dengan memberikan keyakinan, jaminan kualitas, serta prestise tertentu kepada konsumen.

4. Untuk mengendalikan pasar.

\section{PEMBAHASAN}

a. Karakteristik Responden Berdasarkan Umur

Karakteristik responden berdasarkan umur dapat dilihat pada tabel

Tabel 3. Karakteristik Responden Berdasarkan Umur

\begin{tabular}{cccc}
\hline No & Umur & Frekuensi & Jumlah \\
\hline 1 & $17-22$ th & 23 & 23 \\
2 & $23-28$ th & 37 & 37 \\
3 & $29-34$ th & 20 & 20 \\
4 & $35-40$ th & 20 & 20 \\
5 & $>40$ th & - & - \\
\hline
\end{tabular}

Sumber: Hasil pengolahan data primer 2013

Dari Tabel 3 di atas mengenai karakteristik responden berdasarkan umur terlihat bahwa responden yang berumur 23-28 tahun merupakan responden terbanyak yaitu sebanyak 37 orang responden $(37 \%)$. b. Karakteristik Responden Berdasarkan Jenis Kelamin

Karakteristik responden berdasarkan jenis kelamin dapat dilihat pada tabel berikut:

\section{Tabel 4. Karakteristik Responden Berdasarkan Jenis Kelamin}

\begin{tabular}{|c|c|c|c|}
\hline No & Jenis Kelamin & Frekuensi & $\%$ \\
\hline 1 & Pria & 40 & 40 \\
\hline 2 & Wanita & 60 & 60 \\
\hline \multicolumn{2}{|c|}{ Jumlah } & 100 & 100 \\
\hline
\end{tabular}

Sumber: Hasil pengolahan data primer 2013

Dari Tabel 4.2 di atas mengenai karakteristik responden berdasarkan jenis kelamin terlihat bahwa jenis kelamin wanita memiliki jumlah responden terbanyak yang terdiri dari 60 responden $(60 \%)$, dan sisanya responden yang berjenis kelamin pria yaitu terdiri dari 40 responden $(40 \%)$.

c. Karakteristik Responden Berdasarkan

Tingkat Pendidikan

Karakteristik responden berdasarkan tingkat pendidikan dapat dilihat pada tabel berikut:

Tabel 5. Karakteristik Responden Berdasarkan Tingkat Pendidikan

\begin{tabular}{cccc}
\hline No & Tingkat Pendidikan & Frekuensi & \% \\
\hline 1 & SD & 5 & 5 \\
2 & SMP & 10 & 10 \\
3 & SMA & 36 & 36 \\
4 & Diploma & 12 & 12 \\
5 & Sarjana & 37 & 37 \\
\hline
\end{tabular}

Sumber: Hasil pengolahan data primer 2013 
Dari Tabel 5 di atas mengenai karakteristik responden berdasarkan tingkat pendidikan terlihat bahwa responden yang berpendidikan sarjana merupakan responden terbanyak yaitu sebesar 37 responden (37\%), dan yang paling sedikit adalah memiliki pendidikan SD yaitu 5 responden $(5 \%)$.

d. Karakteristik Responden Berdasarkan Pekerjaan

Karakteristik responden berdasarkan pekerjaan dapat dilihat pada tabel berikut

Tabel 6. Karakteristik Responden Berdasarkan Pekerjaan

\begin{tabular}{cccc}
\hline No & Pekerjaan & Frekuensi & \% \\
\hline 1 & pegawai negeri & 25 & 25 \\
2 & pegawai swasta & 17 & 17 \\
3 & Wiraswasta & 15 & 15 \\
4 & pelajar/mahasiswa & 37 & 37 \\
5 & lain-lain & 6 & 6 \\
& Jumlah & 100 & 100 \\
\hline
\end{tabular}

Sumber: Hasil pengolahan data primer 2013

Dari Tabel 6 di atas mengenai karakteristik responden berdasarkan pekerjaan terlihat bahwa responden yang bepekerjaan pelajar/mahasiswa merupakan responden terbanyak yaitu sebesar 37 responden (37\%), dan yang paling sedikit adalah memiliki pekerjaan lain-lain yaitu 6 responden $(6 \%)$. e. Karakteristik Responden Berdasarkan Penghasilan/uang saku per bulan Karakteristik responden berdasarkan penghasilan/uang saku per bulan dapat dilihat pada tabel berikut:

Tabel 7. Karakteristik Responden Berdasarkan Penghasilan/Uang Saku Per Bulan

\begin{tabular}{cccccc}
\hline \multirow{2}{*}{ No } & Jumlah Penghasilan & \multicolumn{2}{c}{ Penghasilan } & \multicolumn{2}{c}{ Uang Saku } \\
\cline { 3 - 6 } & & Frekuensi & \% & Frekuensi & \% \\
\hline 1. & $<$ Rp. 5.000.000 & 5 & 5 & 8 & 13 \\
2 & Rp.1.000.000-Rp.2.000.000 & 30 & 30 & 29 & 59 \\
3 & Rp.2.100.000-Rp.3.000.000 & 22 & 22 & - & 22 \\
4 & $>$ Rp.3.100.000-Rp.5.000.000 & 6 & 6 & - & 6 \\
\hline & Jumlah & 63 & 63 & 37 & 100 \\
\hline
\end{tabular}

Sumber: Hasil pengolahan data primer 2013

Dari Tabel 7 di atas mengenai karakteristik responden berdasarkan penghasilan terlihat bahwa penghasilan Rp.1.000.000Rp.2.000.000 merupakan responden terbanyak yaitu sebesar 30 responden $(30 \%)$ dan uang saku terbanyak yaitu sebesar 29 responden (29\%), dan yang paling sedikit adalah memiliki penghasilan >Rp.3.100.000Rp.5.000.000 sebanyak 6 responden $(6 \%)$. f. Karakteristik Responden Berdasarkan Kegunaan Tablet

Karakteristik responden berdasarkan kegunaan tablet dapat dilihat pada tabel berikut:

Dari Tabel 8 mengenai karakteristik responden berdasarkan kegunaan tablet terlihat bahwa yang menggunakan tablet sebagai social network facebook ,twitter,whatshapp,YM,dll) merupakan 
responden terbanyak yaitu sebesar 47 responden (47\%), dan yang paling sedikit adalah yang menggunakan tablet untuk Browsing internet sebanyak 9 responden $(9 \%)$.

Tabel 8. Karakteristik Responden Berdasarkan Kegunaan Tablet

\begin{tabular}{|c|c|c|c|}
\hline No & Kegunaan Tablet & Frekuensi & Jumlah \\
\hline 1 & $\begin{array}{l}\text { Membantu pekerjaan Adm } \\
\text { kantor/kuliah }\end{array}$ & 44 & 44 \\
\hline 2 & $\begin{array}{l}\text { social network ( facebook } \\
\text {,twitter,whatshapp,YM,dll) }\end{array}$ & 47 & 47 \\
\hline 3 & Browsing internet & 9 & 9 \\
\hline 4 & Kamera dan music & - & - \\
\hline 5 & Lainnya & - & - \\
\hline
\end{tabular}

Sumber: Hasil pengolahan data primer 2013

a. Variabel Kesadaran Merek

Untuk variabel kesadaran merek terdiri atas 8 item pernyataan yang digunakan, untuk lebih jelasnya dapat dilihat pada Tabel 4.8 berikut:

Tabel 9. Distribusi Frekuensi Kesadaran Merek

\begin{tabular}{|c|c|c|c|c|c|c|c|c|c|c|c|c|c|c|c|c|}
\hline \multirow{2}{*}{\begin{tabular}{|c|} 
No \\
Item
\end{tabular}} & \multicolumn{2}{|c|}{ STS } & \multicolumn{2}{|c|}{ TS } & \multicolumn{2}{|c|}{$\mathbf{N}$} & \multicolumn{2}{|c|}{$S$} & \multicolumn{2}{|c|}{ SS } & \multirow{2}{*}{$\mathbf{N}$} & \multirow{2}{*}{$\%$} & \multirow{2}{*}{$\begin{array}{l}\text { Skor } \\
\text { Total }\end{array}$} & \multirow{2}{*}{$\begin{array}{l}\text { Rerata } \\
\text { (mean) }\end{array}$} & \multirow{2}{*}{$\begin{array}{l}\text { AP } \\
(\%)\end{array}$} & \multirow[t]{2}{*}{ Kategori } \\
\hline & $\overline{\mathrm{Fi}}$ & $\%$ & $\mathrm{Fi}$ & $\%$ & $\mathrm{Fi}$ & $\%$ & $\mathrm{Fi}$ & $\%$ & $\mathrm{Fi}$ & $\%$ & & & & & & \\
\hline 1 & 0 & 0 & 0 & 0 & 7 & 7 & 72 & 72 & 21 & 21 & 100 & 100 & 414 & 4.14 & 82.8 & sangat kuat \\
\hline 2 & 0 & 0 & 0 & 0 & 17 & 17 & 48 & 48 & 35 & 35 & 100 & 100 & 418 & 4.18 & 83.6 & sangat kuat \\
\hline 3 & 0 & 0 & 3 & 3 & 29 & 29 & 45 & 45 & 23 & 23 & 100 & 100 & 388 & 3.88 & 77.6 & kuat \\
\hline 4 & 0 & 0 & 2 & 2 & 37 & 37 & 40 & 40 & 21 & 21 & 100 & 100 & 380 & 3.80 & 76.0 & kuat \\
\hline 5 & 0 & 0 & 4 & 4 & 26 & 26 & 50 & 50 & 20 & 20 & 100 & 100 & 386 & 3.86 & 77.2 & kuat \\
\hline 6 & 0 & 0 & 1 & 1 & 28 & 28 & 50 & 50 & 21 & 21 & 100 & 100 & 391 & 3.91 & 78.2 & kuat \\
\hline 7 & 0 & 0 & 3 & 3 & 13 & 13 & 35 & 35 & 49 & 49 & 100 & 100 & 430 & 4.30 & 86.0 & sangat kuat \\
\hline 8 & 0 & 0 & 0 & 0 & 9 & 9 & 51 & 51 & 40 & 40 & 100 & 100 & 431 & 4.31 & 86.2 & sangat kuat \\
\hline \multicolumn{14}{|c|}{ jumlah } & 32.38 & 647.6 & \\
\hline \multicolumn{14}{|c|}{ Rerata kesadaran merek } & 4.05 & 80.95 & sangat kuat \\
\hline
\end{tabular}

Sumber: Hasil Pengolahan Data Primer 2013

Berdasarkan rata-rata penilaian karyawan terhadap kesadaran merek yang disajikan pada tabel di atas, terlihat bahwa skor rata-ratanya adalah 4,05 dengan presentasi (AP) sebesar $80,95 \%$. hal ini menggambarkan bahwa penilaian konsumen kuat terhadap kesadaran merek secara keseluruhan baik dari segi menyadari merek, pengenalan merek, pengingatan kembali merek, dan puncak pikiran dari 8 item pertanyaan dalam variabel kesadaran merek, nilai skor rata-rata tertinggi adalah item pertanyaan no 8 yaitu sebesar 4,31 dengan presentasi $86,2 \%$ sedangkan nilai skor rata-rata yang paling rendah adalah item pernyataan no 4 yaitu sebesar 3,80 dengan presentasi $76 \%$.

b. Variabel Asosiasi Merek

Untuk variabel asosiasi merek terdiri atas 7 item pernyataan yang digunakan, untuk lebih jelasnya dapat dilihat pada Tabel 10 berikut: 


\section{Tabel 10. Distribusi Frekuensi Asosiasi Merek}

\begin{tabular}{|c|c|c|c|c|c|c|c|c|c|c|c|c|c|c|c|c|}
\hline \multirow{2}{*}{$\begin{array}{l}\text { No } \\
\text { Item }\end{array}$} & \multicolumn{2}{|c|}{ STS } & \multicolumn{2}{|c|}{ TS } & \multicolumn{2}{|c|}{$\mathbf{N}$} & \multicolumn{2}{|c|}{$S$} & \multicolumn{2}{|c|}{ SS } & \multirow{2}{*}{$\mathbf{N}$} & \multirow{2}{*}{$\%$} & \multirow{2}{*}{$\begin{array}{l}\text { Skor } \\
\text { Total }\end{array}$} & \multirow{2}{*}{$\begin{array}{l}\text { Rerata } \\
\text { (mean) }\end{array}$} & \multirow{2}{*}{$\begin{array}{l}\text { AP } \\
(\%)\end{array}$} & \multirow[t]{2}{*}{ Kategori } \\
\hline & $\mathrm{Fi}$ & $\%$ & $\mathrm{Fi}$ & $\%$ & $\mathrm{Fi}$ & $\%$ & $\mathrm{Fi}$ & $\%$ & $\mathrm{Fi}$ & $\%$ & & & & & & \\
\hline 1 & 0 & 0 & 0 & 0 & 0 & 0 & 56 & 56 & 44 & 44 & 100 & 100 & 444 & 4.44 & 88.8 & sangat kuat \\
\hline 2 & 0 & 0 & 0 & 0 & 11 & 11 & 48 & 48 & 41 & 41 & 100 & 100 & 430 & 4.30 & 86.0 & sangat kuat \\
\hline 3 & 0 & 0 & 4 & 4 & 8 & 8 & 55 & 55 & 33 & 33 & 100 & 100 & 417 & 4.17 & 83.4 & sangat kuat \\
\hline 4 & 0 & 0 & 9 & 9 & 11 & 11 & 49 & 49 & 31 & 31 & 100 & 100 & 402 & 4.02 & 80.4 & sangat kuat \\
\hline 5 & 5 & 5 & 13 & 13 & 7 & 7 & 49 & 49 & 26 & 26 & 100 & 100 & 378 & 3.78 & 75.6 & kuat \\
\hline 6 & 5 & 5 & 3 & 3 & 3 & 3 & 73 & 73 & 16 & 16 & 100 & 100 & 392 & 3.92 & 78.4 & kuat \\
\hline 7 & 0 & 0 & 0 & 0 & 8 & 8 & 61 & 61 & 31 & 31 & 100 & 100 & 423 & 4.23 & 84.6 & sangat kuat \\
\hline \multicolumn{14}{|c|}{ jumlah } & 28.86 & 577.2 & \\
\hline & & & & & $\operatorname{Re}$ & a as & asin & & & & & & & 4.12 & 82.5 & jangat kuat \\
\hline
\end{tabular}

\section{Sumber: Hasil Pengolahan Data Primer 2013}

Berdasarkan rata-rata penilaian konsumen terhadap asosiasi merek yang disajikan pada tabel di atas, terlihat bahwa skor rata-ratanya adalah 4,12 dengan presentasi (AP) sebesar $82,5 \%$. hal ini menggambarkan bahwa penilaian konsumen kuat terhadap asosiasi merek secara keseluruhan baik dari segi atribut produk, harga relative, gaya hidup pengguna produk, kelas produk. Dari 9 item pertanyaan dalam variabel asosiasi merek, nilai skor rata-rata tertinggi adalah item pertanyaan no 1 yaitu sebesar 4,44 dengan presentasi $88,8 \%$ sedangkan nilai skor rata-rata yang paling rendah adalah item pernyataan no 5 yaitu sebesar 3,78 dengan presentasi 75,6\%.

c. Variabelpersepsi kualitas

Untuk variabel persepsi kualitas terdiri atas 10 item pernyataan yang digunakan, untuk lebih jelasnya dapat dilihat pada Tabel 11 berikut:

Tabel 11. Distribusi Frekuensi Persepsi Kualitas

\begin{tabular}{|c|c|c|c|c|c|c|c|c|c|c|c|c|c|c|c|c|}
\hline \multirow{2}{*}{\begin{tabular}{|l|} 
No \\
Item
\end{tabular}} & \multicolumn{2}{|c|}{ STS } & \multicolumn{2}{|c|}{ TS } & \multicolumn{2}{|c|}{$\mathbf{N}$} & \multicolumn{2}{|c|}{$s$} & \multicolumn{2}{|c|}{ SS } & \multirow{2}{*}{$\mathbf{N}$} & \multirow{2}{*}{$\%$} & \multirow{2}{*}{$\begin{array}{l}\text { Skor } \\
\text { Total }\end{array}$} & \multirow{2}{*}{$\begin{array}{l}\text { Rerata } \\
\text { (mean) }\end{array}$} & \multirow{2}{*}{$\begin{array}{l}\text { AP } \\
(\%)\end{array}$} & \multirow[t]{2}{*}{ Kategori } \\
\hline & $\mathrm{Fi}$ & $\%$ & $\mathrm{Fi}$ & $\%$ & $\mathrm{Fi}$ & $\%$ & $\mathrm{Fi}$ & $\%$ & $\mathrm{Fi}$ & $\%$ & & & & & & \\
\hline 1 & 0 & 0 & 0 & 0 & 0 & 0 & 51 & 51 & 49 & 49 & 100 & 100 & 449 & 4.49 & 89.8 & sangat kuat \\
\hline 2 & 0 & 0 & 0 & 0 & 9 & 9 & 47 & 47 & 44 & 44 & 100 & 100 & 435 & 4.35 & 87.0 & sangat kuat \\
\hline 3 & 0 & 0 & 0 & 0 & 8 & 8 & 53 & 53 & 39 & 39 & 100 & 100 & 431 & 4.31 & 86.2 & sangat kuat \\
\hline 4 & 0 & 0 & 0 & 0 & 0 & 0 & 53 & 53 & 47 & 47 & 100 & 100 & 447 & 4.47 & 89.4 & sangat kuat \\
\hline 5 & 0 & 0 & 5 & 5 & 9 & 9 & 50 & 50 & 36 & 36 & 100 & 100 & 417 & 4.17 & 83.4 & sangat kuat \\
\hline 6 & 0 & 0 & 0 & 0 & 10 & 10 & 57 & 57 & 33 & 33 & 100 & 100 & 423 & 4.23 & 84.6 & sangat kuat \\
\hline 7 & 0 & 0 & 5 & 5 & 0 & 0 & 59 & 59 & 36 & 36 & 100 & 100 & 426 & 4.26 & 85.2 & sangat kuat \\
\hline 8 & 0 & 0 & 0 & 0 & 19 & 19 & 48 & 48 & 33 & 33 & 100 & 100 & 414 & 4.14 & 82.8 & sangat kuat \\
\hline 9 & 0 & 0 & 0 & 0 & 16 & 16 & 40 & 40 & 44 & 44 & 100 & 100 & 428 & 4.28 & 85.6 & sangat kuat \\
\hline 10 & 0 & 0 & 0 & 0 & 0 & 0 & 64 & 64 & 36 & 36 & 100 & 100 & 436 & 4.36 & 87.2 & sangat kuat \\
\hline \multicolumn{14}{|c|}{ jumlah } & 43.06 & 861.2 & \\
\hline & & & & & Rera & pers & psi & itas & & & & & & 4.31 & 86.1 & sangat kuat \\
\hline
\end{tabular}

Sumber: Hasil Pengolahan Data Primer 2013

Berdasarkan rata-rata penilaian konsumen terhadap persepsi kualitas yang disajikan pada tabel di atas, terlihat bahwa skor rata-ratanya adalah 4,31 dengan presentasi (AP) sebesar $86,1 \%$. hal ini menggambarkan bahwa penilaian konsumen kuat secara keseluruhan baik dari segi alasan untuk membeli, diferensiasi posisi, harga optimum, manfaat saluran distribusi dan perluasan merek dari 10 item pertanyaan dalam variabel persepsi kualitas, nilai skor rata-rata tertinggi adalah item pertanyaan no 1 yaitu sebesar 4,49 dengan presentasi $89,8 \%$. sedangkan nilai skor rata-rata yang paling rendah adalah item pernyataan 8 yaitu sebesar 4,14 dengan presentasi $82,8 \%$

d. Variabel keputusan pembelian

Untuk variabelkeputusan pembelian terdiri atas 9 item pernyataan yang 
digunakan, untuk lebih jelasnya dapat

dilihat pada Tabel 12 berikut:

Tabel 12. Distribusi Frekuensi Keputusan Pembelian

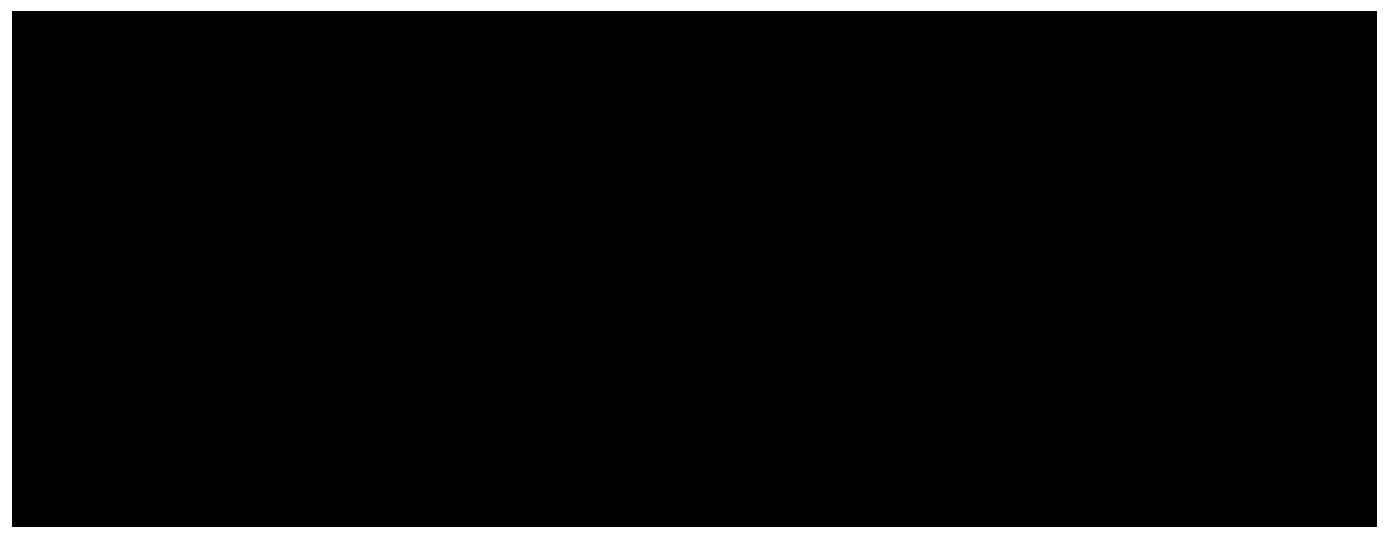

Sumber: Hasil Pengolahan Data Primer 2013

Berdasarkan rata-rata penilaian
konsumen terhadap keputusan
pembelian yang disajikan pada tabel di
atas, terlihat bahwa skor rata-ratanya
adalah 4,32 dengan presentasi (AP)
sebesar $\quad 86,4 \%$. menggambarkan bahwa penilaian konsumen kuat secara keseluruhan baik dari segi adanya pengenalan masalah, pencarian informasi, evaluasi alternative, keputusan pembelian dan perilaku pasca pembelian. Dari 9 item pertanyaan dalam variabel keputusan pembelian skor rata-rata tertinggi adalah item pertanyaan no 5 yaitu sebesar 4,50 dengan presentasi $90 \%$. sedangkan nilai skor rata-rata yang paling rendah adalah item pernyataan no 6 yaitu sebesar 4,18 dengan presentasi $83,6 \%$.

\section{PENUTUP}

\section{Kesimpulan}

Dari hasil pengujian hipotesis yang telah dilakukan maka dapat disimpulkan :Secara parsial kesadaran merek berpengaruh terhadap keputusan pembelian PC Tablet Samsung Galaxi di Kota Padang.Secara parsial asosiasi merek berpengaruh terhadap keputusan pembelian PC Tablet Samsung Galaxi di Kota Padang.Secara parsial persepsi kualitas berpengaruh terhadap keputusan pembelian PC Tablet Samsung Galaxi di Kota Padang.

Saran

Berdasarkan kesimpulan yang diperoleh di atas, untuk dapat meningkatkan keputusan pembelian, maka disarankan agar: Perusahaan yang menjual PC Tablet harus terus mempehatikan kesadaran merek, asosiasi merek dan persepsi kualitas konsumen terhadap merek sebuah PC Tablet sehingga akan terus berpengaruh terhadap keputusan pembelian. Dan juga perusahaan yang menjual PC Tablet harus terus mempertahankan merek PC Tablet yang dijualnya sehingga merek itu memang merek yang menjadi pilihan konsumen dalam pembelian sebuah PC Tablet.

\section{DAFTAR PUSTAKA}

\subsection{2/economica.2014.v2.i2.223}

Alma, Buchari. 2007. Manajemen Pemasaran dan Pemasaran Jasa. Bandung: Alfabeta.

Astuti, Sri Wahjuni \& I Gde Cahyadi 2007. Pengaruh Elemen Ekuitas Merek Terhadap Rasa Percaya Diri Pelanggan di Surabaya Atas Keputusan Pembelian Sepeda Motor Honda 
Durianto, Darmadi, Sugiarto, Tony Sitinjak, 2001. Strategi Menaklukkan Pasar Melalui Riset Ekuitas dan Perilaku Merek. Jakarta: Gramedia Pustaka Utama.

Fadli dan Inneke Qamariah, 2008. Analisis Pengaruh Faktor-Faktor Ekuitas Merek Sepeda Motor Merek Honda Terhadap Keputusan Pembelian (Studi Kasus Pada Universitas Sumatera Utara).

Ghozali, Imam, 2002. Aplikasi Analisis Multivariate Dengan Program SPSS. Badan Penerbit Universitas Diponegoro.

Hartiningtiyas, Ayu \& M. Assegaff. 2010. Pengaruh Brand Awareness, Brand Association Dan Perceived Quality Terhadap Keputusan Pembelian Sepeda Motor Bebek 4-Tak Merek Honda (Studi Kasus Di Kecamatan Kaliwungu Kabupaten Kendal). EKOBIS Vol. 11 No. 2 Juli 2010 : 151-159

Istijanto. 2005. Aplikasi Praktis Riset Pemasaran. Gramedia Pustaka Utama : Jakarta.

Kotler, Philip \& Armstrong, Gary. 2001. Prinsip-Prinsip Pemasaran. Edisi Kedelapan Jilid 1. Jakarta : Erlangga.

Kotler, Philip. 2005. Manajemen Pemasaran. Edisi Kesebelas. Jilid 1. Jakarta: indeks

Kotler, Philip, dan Kevin Lane Keller. 2009. Manajemen Pemasaran, Edisi 13, Jilid 1 \& 2 Penerbit : Erlangga

Peter, J. Paul dan Olson, Jerry C. 1999. Consumer Behavior Perilaku Konsumen dan Strategi Pemasaran. Edisi 4 Cetakan 1, Jilid 1. Jakarta : Erlangga.

Qamariah, Inneke dan Fadli. Analisis Pengaruh Faktor-Faktor Penentu Ekuitas Merek Sepeda Motor Merek Honda Terhadap Keputusan Pembelian (Studi Kasus Pada Universitas Sumatera Utara). Jurnal Manajemen Bisnis, Volume 1, Nomor 2, Mei 2008 : 48 -58

Rangkuti, Freddy. 2009. The Power of Brands Teknik Mengelola Brand Equity dan Strategi Pengembangan Merek plus Analisis Kasus dengan SPSS. Jakarta : Gramedia Pustaka Utama
Riduwan dan Akdon. 2007. Rumus dan Data dalam Analisis Statistika, Bandung : Alfabeta

Rully, Arlan Tjahyadi. 2006. "Brand Trust Dalam Konteks Loyalitas Merek: Peran karakteristik Merek, Karakteristik Perusahaan Dan Karakteristik Hubungan Pelanggan-Merek." Jurnal Manajemen, Vol. 6, No.1

Santoso, Singgih. 2001. Buku Latihan SPSS. Edisi Kedua. Jakarta: Elex Media Komputindo.

Schiffman, Leon G. and Leslie Lazar Kanuk. 2007. Perilaku Konsumen . Edisi Ketujuh. Jakarta: Indeks Kelompok Gramedia.

Setiadi, Nugroho J. 2003. Perilaku Konsumen : Perspektif Kontemporer Pada Motif, Tujuan, dan Keinginan Konsumen. Edisi Revisi, Cetakan ke-4. Jakarta : Kencana.

Simamora, Bilson. 2004. Mengenal Kotak Hitam Perilaku Konsumen. Jakarta: Gramedia Utama.

Sri Wahjuni Astute \& I Gde Cahyadi. 2007. Pengaruh Elemen Ekuitas Merek Terhadap Rasa Percaya Diri Pelanggan Di Surabaya Atas Keputusan Pembelian Sepeda Motor Honda. Majalah Ekonomi. Tahun XVII, No. 2 Agustus 2007.

Sugiyono, 2003. Metode Penelitian Bisnis. Cetakan Kelima. Alfabeta, Bandung

Tjiptono, Fandy. 2008. Strategi Pemasaran, Edisi II. Jakarta: Penerbit Andi Yogyakarta

Umar, Husain. 2011. Metode Penelitian Untuk Skripsi Dan Tesis Bisnis. Edisi Kedua. Jakarta : Rajawali Pers.

Widjaja, Maya, Serli Wijaya dan Regina Jokom. 2007. Analisis Penilaian Konsumen terhadap Ekuitas Merek Coffee Shops di Surabaya, Jurnal Manajemen Perhotelan, 3 (2), hal. 89:101 